\title{
Marriage contributes to higher obesity risk in China: findings from the China Health and Nutrition Survey
}

\author{
Jinli Liu ${ }^{1}$, Malgorzata A. Garstka ${ }^{2}$, Zhonglin Chai ${ }^{3}$, Yifan Chen ${ }^{4}$, Veronika Lipkova ${ }^{4}$, Mark E. Cooper ${ }^{3}$, \\ Kingsley Katleho Mokoena ${ }^{5}$, Youfa Wang ${ }^{6}$, Lei Zhang ${ }^{1,7,8,9}$
}

${ }^{1}$ China-Australia Joint Research Centre for Infectious Diseases, School of Public Health, Xi'an Jiaotong University Health Science Centre, Xi'an, China; ${ }^{2}$ Core Research Laboratory, Department of Endocrinology, National \& Local Joint Engineering Research Center of Biodiagnosis and Biotherapy, The Second Affiliated Hospital, School of Medicine, Xi'an Jiaotong University, Xi'an, China; ${ }^{3}$ Department of Diabetes, Central Clinical School, Monash University, Melbourne, Australia; ${ }^{4}$ Medical Sciences Division, University of Oxford, Oxford, UK; ${ }^{5}$ School of Public Health, Xi'an Jiaotong University Health Science Centre, Xi'an, China; ${ }^{6}$ Global Health Institute, School of Public Health, Xi'an Jiaotong University Health Science Center, Xi'an, China; ${ }^{7}$ Melbourne Sexual Health Centre, Alfred Health, Melbourne, Australia; ${ }^{8}$ Central Clinical School, Faculty of Medicine, Monash University, Melbourne, Australia; ' Department of Epidemiology and Biostatistics, College of Public Health, Zhengzhou University, Zhengzhou, China

Contributions: (I) Conception and design: L Zhang, J Liu; (II) Administrative support: L Zhang; (III) Provision of study materials or patients: L Zhang, J Liu; (IV) Collection and assembly of data: J Liu, Y Chen, ME Cooper; (V) Data analysis and interpretation: L Zhang, J Liu, MA Garstka, Z Chai, Y Chen, ME Cooper; (VI) Manuscript writing: All authors; (VII) Final approval of manuscript: All authors.

Correspondence to: Prof. Lei Zhang. China-Australia Joint Research Centre for Infectious Diseases, School of Public Health, Xi'an Jiaotong University Health Science Center, Xi'an, China. Email: lei.zhang1@xjtu.edu.cn.

Background: To investigate the association between marriage and the prevalence of overweight and obesity in China.

Methods: We conducted cross-sectional and retrospective cohort analyses using a nationwide sample of 36,310 individuals from the China Health and Nutrition Survey [2004-2015].

Results: The prevalence of overweight and obesity increased from $28.7 \%$ to $36.7 \%$ and from $8.0 \%$ to $14.5 \%$ between 2004 and 2015, respectively. The cross-sectional analysis showed that married individuals were at a higher risk of being overweight $(\mathrm{OR}=2.18 ; 95 \% \mathrm{CI}, 1.90-2.51)$ or obese (OR $=1.95 ; 1.57-2.43)$ than never-married individuals. Divorced/widowed individuals were also at a greater risk of being overweight $(\mathrm{OR}=1.80 ; 1.51-2.13)$ or obese $(\mathrm{OR}=1.67 ; 1.28-2.17)$ than never-married individuals. Retrospective cohort analysis showed that individuals who married during the study were 1.55 (1.13-2.11) times more likely to be overweight than those who remained never-married. Compared to those who remained nevermarried, individuals who remained married were $1.71(1.42-2.07)$ and 1.45 (1.11-1.89) times more likely to be overweight and obese. Individuals who became divorced or widowed were more likely to be overweight $(\mathrm{RR}=1.59 ; 1.18-2.15)$ or obese $(\mathrm{RR}=1.63 ; 1.08-2.46)$ than those who remained never-married. However, the risk of being overweight or obese among those who became divorced or widowed did not differ significantly from the risk among those who remained married.

Conclusions: Marriage contributes to an increased risk of overweight and obesity in China; however, this risk is not significantly reduced by exiting a marriage.

Keywords: Overweight; obesity; BMI; marital status

Submitted Jun 07, 2020. Accepted for publication Nov 08, 2020.

doi: $10.21037 /$ atm-20-4550

View this article at: http://dx.doi.org/10.21037/atm-20-4550 


\section{Introduction}

The association of obesity with marriage has been an important topic of interest in studies to date (1-3). Obesity has become a major global public health issue $(4,5)$. Obesity with a high body mass index $(B M I \geq 28.0)$ is a risk factor for various chronic diseases, including cardiovascular diseases (6), diabetes mellitus (7), stroke (8), chronic kidney disease (9), cancer (10), musculoskeletal disorders (11) and multimorbidities (12-14). Accumulating evidence suggests that marital status is closely associated with weight changes (15-17), with married individuals reported to gain more bodyweight than never-married individuals (16-20). The underlying cause of weight gain during marriage is multifactorial and can result from complex interactions between biological, psychological, social, and cultural factors (21-24). To date, the majority of studies on the association of marital status with obesity have been conducted in developed countries $(1,2)$. However, the rapid escalation of the global obesity epidemic has seen interest increase in developing countries, with greater efforts being made to understand the association between marriage and obesity.

The prevalence of overweight and obesity in China is reported to be growing. From 2004 to 2011, the proportion of overweight Chinese people increased from 35.4\% to $38.8 \%$, and the proportion of obese Chinese people increased from $9.2 \%$ to $14.0 \%$ (25). For the rapidly aging Chinese population, the prevention of obesity plays an increasingly important role in preventing a broad spectrum of chronic diseases. Over the past 2 decades, there has been a significant shift in Chinese family structures. Statistical evidence from the Ministry of Civil Affairs showed a decline in the annual marriage rate from $14.4 \%$ o to $7.30 \%$, while the divorce rate rose from $1.92 \%$ o to $3.20 \%$ o during 1998-2018 (26). Moreover, between 1980 and 2010, the mean age at first marriage increased from 25.0 to 26.0 and 23.0 to 23.9 years for men and women, respectively (27). Transitions in family structure, such as divorce, disrupt family relationships, necessitating considerable reorganization of family roles, and increasing stress (28). Marital transitions as social factors may influence body weight in adulthood (29). Therefore, Chinese family structure changes may have affected the population's BMI and thus demand a thorough investigation.

Only a few studies have investigated the relationship between marriage and BMI in the Chinese population. $\mathrm{Xu}$ et al. reported that both body weight and shape have important implications for marital success (30). Liao et al. found that married twins had higher BMI than unmarried twins, independent of genetic and shared environmental factors in both sexes. In contrast, genetic and shared environmental factors contributed to education-associated BMI disparities in females (19).

The current study aimed to investigate the temporal trend of BMI in the Chinese population and the association between BMI and marital status. The study was based on 5 nationwide longitudinal surveys from the China Health and Nutrition Survey (CHNS), which involved 36,310 individuals in the cross-sectional study and 9,646 individuals in the retrospective cohort study. We present the following article following the STROBE reporting checklist (available at http://dx.doi.org/10.21037/atm-20-4550).

\section{Methods}

\section{Study design and etbics}

The CHNS was a longitudinal survey to examine the health and nutritional status of China's general population. The survey, which was initiated in 1989 , comprised 10 waves (in 1989, 1991, 1993, 1997, 2000, 2004, 2006, 2009, 2011, and 2015) and surveyed 3 municipalities and 12 provinces: Beijing, Chongqing, Shanghai, Heilongjiang, Liaoning, Shandong, Jiangsu, Henan, Hubei, Hunan, Guangxi, Guizhou, Shaanxi, Yunnan, and Zhejiang (with the last 3 provinces added in 2015).

The original population study employed a multi-stage, random-cluster sampling design for participant recruitment [details available elsewhere (17)]. The present study included only adult participants (aged $\geq 18$ ) who participated in the surveys from 2004 to 2015 . Our study consisted of 2 parts. Firstly, to investigate the association between marital status and participants' BMI at the time of the surveys, we pooled the data from all 5 surveys together as a cross-sectional study. A total of 36,310 participants were included $(6,542,6,344,6,881,9,505$, and 7,038 subjects for the years 2004, 2006, 2009, 2011, and 2015, respectively). Secondly, to investigate the association between marital status changes and BMI, we established a retrospective cohort by including participants who had participated in at least 2 rounds of the CHNS surveys between 2004 and 2015 (Table S1). Pregnant women, lactating mothers, and individuals with incomplete records of key variables were excluded from the study's cross-sectional and retrospective cohort parts. In this study, less than $5 \%$ of all participants 
had missing variables. The study was conducted following the Declaration of Helsinki (as revised in 2013). The Institutional Review Committees approved the survey protocols, instruments, and the process for obtaining informed consent of the University of North Carolina at Chapel Hill, NC, USA, and the China National Institute of Nutrition and Food Safety at the Chinese Center for Disease Control and Prevention, Beijing, China. All participants had given written informed consent before taking part in the surveys.

\section{Predictors}

Participants were categorized into 7 age groups of 18 29, 30-39, 40-49, 50-59, 60-69, 70-79, and 80 years. According to the Chinese residents' income percentiles from the Chinese Statistical Yearbook, income levels were categorized as "low", "middle", and "high" (31). Education levels were categorized as low (primary education and below), middle (secondary school), and high (university/ higher). For the cross-sectional analysis, marital status was classified into 3 categories: never-married, married, and divorced/widowed. For the retrospective cohort analysis, marital status changes were categorized as "remained nevermarried", "got married", "remained married", and "became divorced/widowed". According to the recommended criteria for Chinese people, underweight individuals (BMI $<18.5 \mathrm{~kg} / \mathrm{m}^{2}$ ), normal weight (BMI $18.5-23.9 \mathrm{~kg} / \mathrm{m}^{2}$ ), overweight (BMI $24.0-27.9 \mathrm{~kg} / \mathrm{m}^{2}$ ), and obese (BMI $\geq 28 \mathrm{~kg} / \mathrm{m}^{2}$ ) were assessed (32). Lifestyle behaviors included smoking (yes or no), alcohol consumption (yes or no), and sleep duration ( $\leq 5,6-8$, and $\geq 9$ hours).

\section{Statistical analysis}

For descriptive analyses, categorical variables were presented as percentages. The prevalence of overweight and obesity among the participants was analyzed, and the $95 \%$ confidence intervals (CI) were estimated for different marital statuses. In both the cross-sectional and retrospective cohort analyses, the multinomial logistic regression model was used to control confounding factors (19). A set of models was used. In the cross-sectional analysis, model 1 was adjusted for basic demographic characteristics including sex and age; model 2 included education level, income level, residence, and employment status in addition to the covariates included in model 1; and model 3 added sleep duration, smoking, and alcohol consumption to the model 2 covariates. In the retrospective cohort analysis, the 3 models also included the cohort analysis duration as an additional confounding variable. Odds ratios (ORs) with $95 \%$ confidence intervals (CIs) were calculated. Statistical significance was indicated by 2 -tailed $\mathrm{P}$ values $<0.05$. Data analysis was conducted using SAS version 9.4 (SAS Institute, Cary, USA) and R software, version 3.5.2.

\section{Results}

\section{Demographic characteristics}

A total of 36,310 individuals participated in 5 crosssectional surveys, of whom 9,646 individuals who completed the surveys at least twice were eligible for inclusion in the retrospective cohort analysis. The basic demographic characteristics of the survey participants are presented in Table 1. The proportions of men and women were similar. Between 2004 and 2015, the median age of participants increased from 48 to 53 years old. The majority of participants were educated to at least middle/high school level $(54.7 \%)$. The proportions of participants living in rural and urban areas were similar, and the majority of participants (88.2\%) were married and employed (68.2\%) at the time of the survey. Between 2004 and 2015, the proportion of overweight individuals increased from $28.7 \%$ to $36.7 \%$, and the proportion of obese individuals increased from $8.0 \%$ to $14.5 \%$. During the same period, the proportion of underweight individuals decreased from $5.5 \%$ to $3.9 \%$ (Table 1, Figure 1A).

\section{Married individuals: the prevalence of overweight and obesity}

In a crude analysis (Table S2, Figure $1 B$ ), married men showed a consistently higher combined prevalence of overweight and obesity than never-married or divorced/ widowed men [45.3\% (44.5-46.0\%) versus $28.0 \%$ (25.3$30.7 \%$ ) and $37.9 \%(34.6-41.1 \%)]$. A similar pattern was observed in women $[42.5 \%(41.7-43.3 \%)$ versus $13.8 \%$ $(11.2-16.4 \%)$ and $42.2 \%(39.8-44.5 \%)]$. Never-married and married men showed a significantly higher prevalence of overweight and obesity than their female counterparts. Conversely, divorced/widowed men were less likely to be overweight or obese than divorced/widowed women.

After adjusting for demographic characteristics and lifestyle factors (Figure 2A, model 3), married individuals 
Table 1 Basic characteristics of study participants of the China Health and Nutrition Survey [2004-2015], stratified by study years of the longitudinal study $(\mathrm{N}=36,310)$

\begin{tabular}{|c|c|c|c|c|c|}
\hline Variable & $2004(n=6,542)$ & $2006(n=6,344)$ & $2009(n=6,881)$ & $2011(n=9,505)$ & $2015(n=7,038)$ \\
\hline Male & 3,265 (49.9) & $3,171(50.0)$ & $3,484(50.6)$ & $4,712(49.6)$ & $3,602(50.2)$ \\
\hline Female & $3,277(50.1)$ & $3,173(50.0)$ & 3,397 (49.4) & $4,793(50.4)$ & $3,436(49.8)$ \\
\hline \multicolumn{6}{|l|}{ Age groups, n (\%) } \\
\hline 30-39 & $1,300(19.9)$ & $1,205(19.0)$ & $1,085(15.8)$ & $1,372(14.4)$ & $872(12.4)$ \\
\hline $40-49$ & $1,645(25.1)$ & $1,555(24.5)$ & $1,717(25.0)$ & $2,339(24.6)$ & $1,501(21.3)$ \\
\hline $50-59$ & $1,586(24.3)$ & $1,636(25.8)$ & $1,734(25.2)$ & 2,394 (25.2) & $1,850(26.3)$ \\
\hline $60-69$ & $885(13.5)$ & $922(14.5)$ & $1,150(16.6)$ & $1,756(18.5)$ & $1,574(22.3)$ \\
\hline \multicolumn{6}{|l|}{ Education, n (\%) } \\
\hline Primary school and below & $2,821(43.1)$ & $2,550(40.2)$ & 2,729 (39.7) & $3,199(33.7)$ & 1,391 (19.8) \\
\hline Middle/high school & $3,410(52.1)$ & $3,366(53.1)$ & $3,716(54.0)$ & $4,961(52.2)$ & $4,413(62.7)$ \\
\hline University/higher & $311(4.8)$ & $428(6.7)$ & $436(6.3)$ & $1345(14.1)$ & $1234(17.5)$ \\
\hline \multicolumn{6}{|l|}{ Residence, n (\%) } \\
\hline Urban & $2,748(42.0)$ & $2,648(41.7)$ & $2,820(41.0)$ & $5,005(52.7)$ & $3,781(53.7)$ \\
\hline Rural & $3,794(58.0)$ & $3,696(58.3)$ & $4,061(59.0)$ & $4,500(47.3)$ & 3,257 (46.3) \\
\hline \multicolumn{6}{|l|}{ Marital status, n (\%) } \\
\hline \multicolumn{6}{|l|}{ Employment status, n (\%) } \\
\hline Employed & $4,681(71.6)$ & $4,535(71.5)$ & $4,964(72.1)$ & $6,584(69.3)$ & $3,992(56.7)$ \\
\hline Annual income (RMB), median (IQR) & $4,916[7,615]$ & $6,753[9,383]$ & $11,470[13,586]$ & $18,000[18,600]$ & $27,000[27,827]$ \\
\hline \multicolumn{6}{|l|}{ BMI $\left(\mathrm{kg} / \mathrm{m}^{2}\right), \mathrm{n}(\%)$} \\
\hline Underweight $(<18.5)$ & $358(5.5)$ & $348(5.5)$ & $396(5.8)$ & $406(4.3)$ & $278(3.9)$ \\
\hline Normal weight (18.5-23.9) & $3,781(57.8)$ & $3,606(56.8)$ & $3,394(53.7)$ & $4,803(50.5)$ & $3,151(44.8)$ \\
\hline Overweight (24-27.9) & $1,880(28.7)$ & $1,888(29.8)$ & $2,160(31.4)$ & $3,177(33.4)$ & $2,586(36.7)$ \\
\hline Obesity ( $\geq 28)$ & $523(8.0)$ & $502(7.9)$ & $631(9.2)$ & $1,119(11.8)$ & $1,023(14.5)$ \\
\hline
\end{tabular}

Table 1 (continued) 
Table 1 (continued)

\begin{tabular}{|c|c|c|c|c|c|}
\hline Variable & $2004(n=6,542)$ & $2006(n=6,344)$ & $2009(n=6,881)$ & $2011(n=9,505)$ & $2015(n=7,038)$ \\
\hline Low income & 1,909 (29.2) & $1,750(27.6)$ & 1,298 (18.9) & $1,568(16.5)$ & 816 (11.6) \\
\hline Middle income & 3,655 (55.9) & $3,592(56.6)$ & $4,303(62.5)$ & 6,067 (63.8) & $4,730(67.2)$ \\
\hline High income & 978 (14.9) & 1,002 (15.8) & $1,280(18.6)$ & $1,870(19.7)$ & $1,492(21.2)$ \\
\hline$\leq 5$ & $91(1.4)$ & $75(1.2)$ & $139(2.0)$ & $285(3.0)$ & $179(2.5)$ \\
\hline $6-8$ & $4,562(69.7)$ & $4,614(72.7)$ & $5,290(76.9)$ & 7,571 (79.7) & $5,850(83.1)$ \\
\hline$\geq 9$ & 1,889 (28.9) & 1,655 (26.1) & $1,452(21.2)$ & 1,649 (17.3) & $1,009(14.4)$ \\
\hline \multicolumn{6}{|l|}{ Smoking, $\mathrm{n}(\%)$} \\
\hline \multicolumn{6}{|c|}{ Alcohol consumption, n (\%) } \\
\hline No & $4,216(64.4)$ & 4,096 (64.6) & 4,379 (63.6) & $6,012(63.3)$ & $4,883(69.4)$ \\
\hline Yes & 2,326 (35.6) & 2,248 (35.4) & 2,502 (36.4) & 3,493 (36.7) & 2,155 (30.6) \\
\hline
\end{tabular}

RMB, Renminbi; IQR, inter-quartile range; BMI, body mass index.
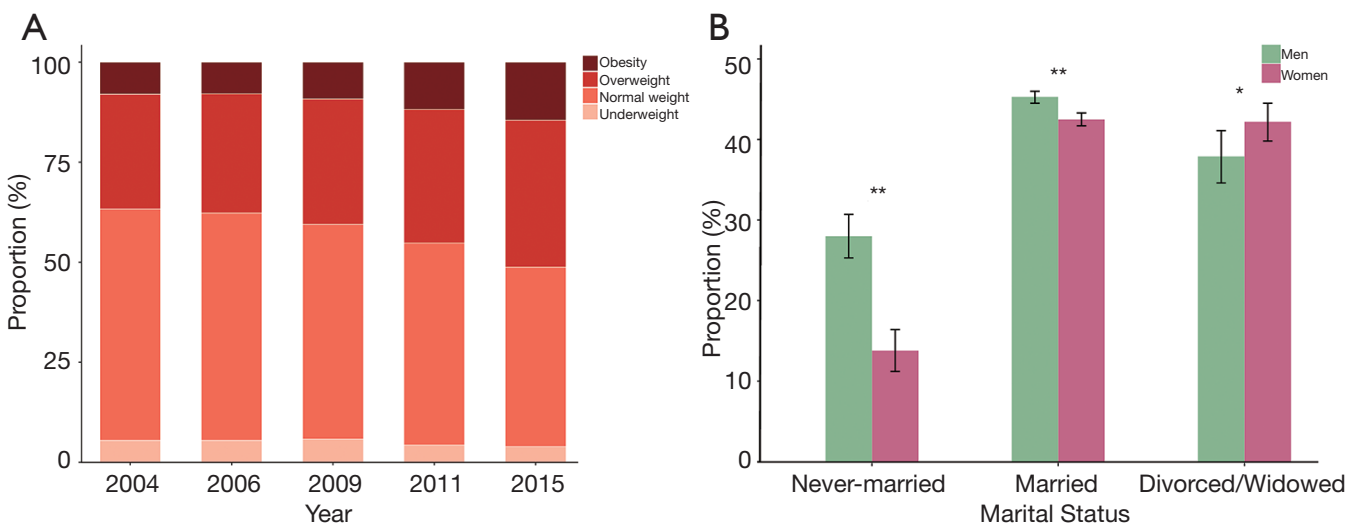

Figure 1 Prevalence [\%, 95\% confidence interval (CI)] of overweight and obesity (BMI $\geq 24.0)$ by (A) years and (B) marital status and sex among participants of the CHNS in a pooled dataset of the 5 consecutive longitudinal surveys $(\mathrm{N}=36,310)\left({ }^{* *} \mathrm{P}<0.001,{ }^{*} \mathrm{P}<0.05\right)$.

were at a higher risk of being overweight (OR, 2.18; $95 \%$ CI, 1.90-2.51) or obese (OR, 1.95; 95\% CI, 1.57-2.43) than never-married individuals. Divorced/widowed individuals were also at a greater risk of being overweight (OR, 1.80; 95\% CI, 1.51-2.13) or obese (OR, 1.67; 95\% CI, 1.28-2.17) than never-married individuals. In contrast, the risk of being underweight among married or divorced/widowed individuals was significantly lower than that among individuals who never married (Figure 2A, model 3).

\section{Entering into a marriage: the risk of overweight and obesity}

After adjusting for the period between the surveys taken by each participant in the cohort, as well as demographic characteristics, and lifestyle factors (Figure 2B, model 3), 


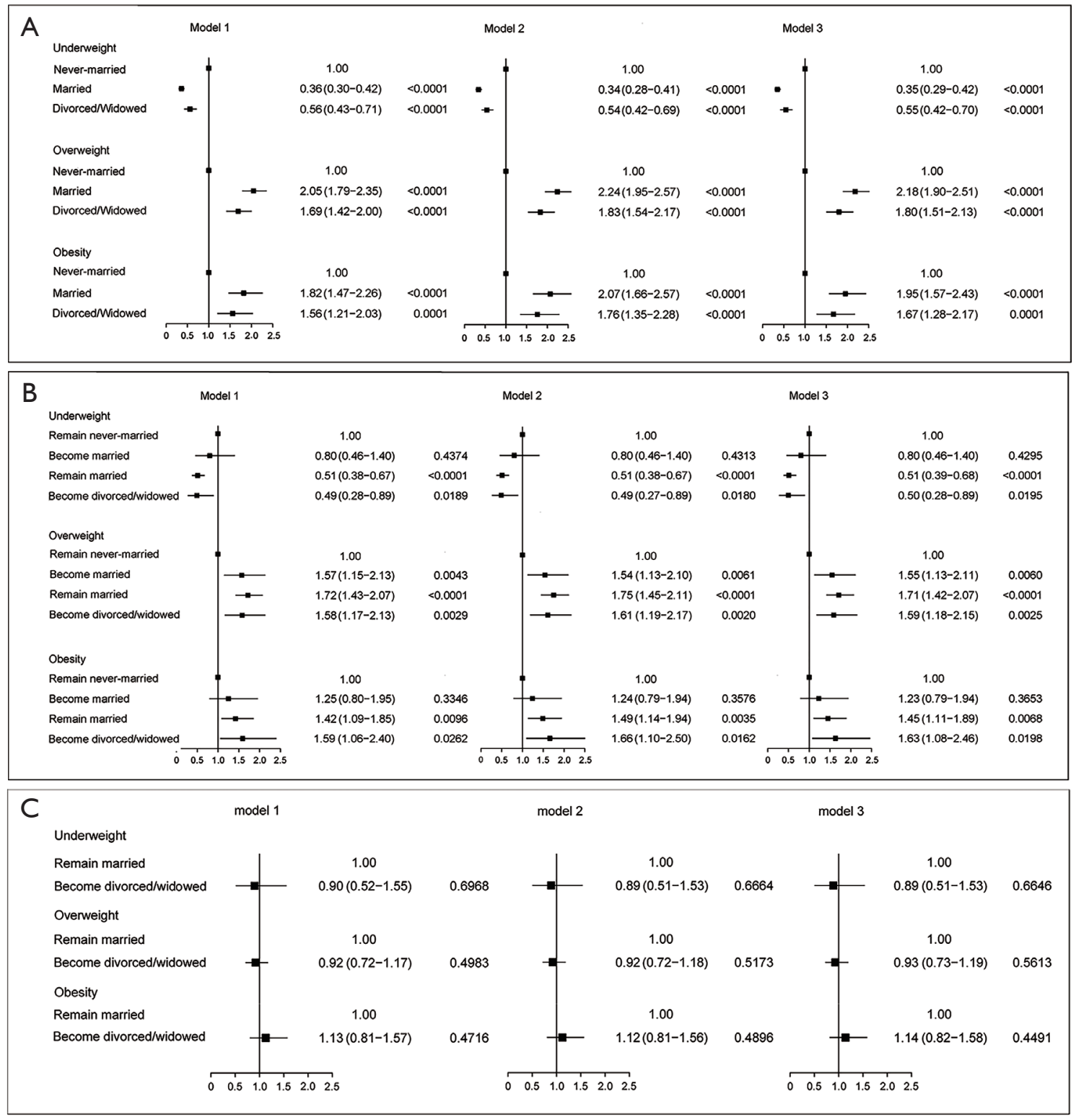

Figure 2 Risk of underweight, overweight, and obesity among CHNS participants stratified by current marital status or change in marital status in a pooled dataset of 5 consecutive longitudinal surveys. (A) The risk of underweight, overweight and obesity by marital status $(\mathrm{N}=36,310)$ in a pooled cross-sectional analysis; (B) the risk of underweight, overweight, and obesity according to the changes in marital status $(n=9,646)$ in 2 consecutive surveys based on a cohort study; (C) the risk of underweight, overweight, and obesity among participants who became divorced/widowed compared with that among participants who remained married ( $N=8,594)$ in 2 consecutive surveys based on a cohort study. Model 1 adjusted for sex and age at baseline in (A) and adjusted for sex and age, and the duration in the cohort at baseline in (B) and (C). Model 2 adjusted for the variables in model 1 as well as education level, income level, residence, and employment status at baseline. Model 3 adjusted for the variables in model 2 as well as sleep duration, smoking, and alcohol consumption at baseline. CHNS is the abbreviation for China Health and Nutrition Survey. Risk is represented by risk ratio (RR) with and 95\% confidence intervals (CIs). 
the retrospective cohort analysis showed that individuals who entered into a marriage had a higher risk of becoming overweight or obese. Compared with individuals who remained never-married, individuals who became married had a significantly higher risk of being overweight (RR, 1.55 ; 95\% CI, 1.13-2.11). Individuals who remained married also had a significantly higher risk of being overweight (RR, 1.71; 95\% CI, 1.42-2.07) or obese (RR, 1.45; 95\% CI, 1.11-1.89) than those who remained never-married (Figure 2B). Furthermore, individuals who became divorced/widowed were more likely to be overweight (RR, 1.59; 95\% CI, 1.18-2.15) or obese (RR, 1.63 ; 95\% CI, 1.08-2.46) than those who remained nevermarried. Participants who remained married (RR, 0.51; 95\% CI, 0.39-0.68) or became divorced/widowed (RR, $0.50 ; 95 \%$ CI, $0.28-0.89$ ) were significantly less likely to be underweight than those who remained never-married (Figure 2B, model 3). No significant difference was found in the risk of being underweight, overweight, or obese between those who became divorced/widowed and those who remained married (Figure 2C). There was also no significant difference in the risk of being overweight or obese between those who remained married and those who became married. However, people who remained married (RR, 0.56; 95\% CI, 0.34-0.93) were significantly less likely to be underweight than those who became married (Table S3, Model 3).

\section{Discussion}

Our study showed the impact of marital status on BMI among Chinese adults in a large population cohort. We demonstrated that the prevalence of overweight and obesity in China increased substantially between 2004 and 2015 . This observation is consistent with the findings of several previous studies $(4,33,34)$ and reflects an intertwining trend between the overweight and obesity epidemic and economic development. Through both cross-sectional and retrospective cohort analyses, we demonstrated that married individuals and those remaining marriage were at a higher risk of being overweight or obese than individuals with another marital status. In contrast, the underweight risk for individuals who remained married and those who divorced/ widowed was reduced. Moreover, our cross-sectional analysis found that the risk of overweight and obesity as similar in divorced/widowed and married individuals. Furthermore, in the retrospective analysis, the risk of overweight and obesity did not differ between individuals who exited marriage due to divorce or loss of a spouse and those who remained married.

Based on our cross-sectional analysis, the prevalence of overweight and obesity in men was higher than that in women. Divorced/widowed men were less likely to be overweight/obese than their female counterparts. Our findings contradicted those of other studies that reported the prevalence of overweight or obesity among women to be consistently higher than that among men regardless of marital status (16). Sex is a stratifying factor for many health issues; it often interacts with other factors, including ethnicity and biological, environmental, lifestyle, and social factors (35). We hypothesized that marriage impacts men and women differently in Chinese society. Being divorced or widowed may have more pronounced adverse physical and psychological effects on men than women (36). In men, BMI decreases in the period following a divorce, which has been reported previously (2), and there are 2 plausible explanations for this. First, Chinese men are known to be more reliant on their partners' physical and emotional care than women. Thus, Chinese men often take a longer time to recover emotionally after a divorce or a partner's death. This suggests that those who become divorced or widowed may experience persistent psychological distress, which could explain the significantly lower prevalence of overweight and obesity among divorced/widowed men compared to women. Second, an individual's change in mood resulting from divorce or the death of a partner may result in reduced levels of exercise. However, whether these factors contributed to the findings of the present study requires further investigation.

Our study revealed that married individuals and those who entered into marriage were at a higher risk of being overweight or obese, which was consistent with previous findings. A Chinese National Twin Registry study on 10,448 same-sex twin pairs reported that married twins had a significantly higher BMI than their never-married counterparts (19). There are 2 possible explanations for this. Firstly, never-married individuals may care more about managing their weight in order to attract potential partners. Secondly, due to having more family responsibilities, married individuals have less time for physical activities. Their dietary pattern is more likely to change, and weight control could become less consistent after entering marriage (20).

Our cross-sectional study demonstrated that the risk of being overweight or obese was similar between individuals who were divorced or widowed and those who were married. This effect among married and once-married 
individuals was further supported by the results of our retrospective cohort analysis, which showed that the end of a marriage due to divorce or loss of a spouse did not change the risk of overweight or obesity. A previous study reported that exiting a marriage was associated with weight loss (37). However, the current study suggested only a small, statistically insignificant decline in overweight and obesity risk. This might reflect that bodyweight gained during a marriage cannot be easily reduced, even after the trauma of becoming divorced or widowed. Besides, acute weight loss, if any, due to divorce or loss of a spouse might be temporary, and the 2- or 3-year intervals between the longitudinal surveys may have been long enough for participants to recover and regain body weight.

The current study has several limitations. First, study participants were selected from specific Chinese provinces. Hence, the sample may not be representative of the general Chinese population. Second, our study did not consider the various ethnic groups of China, and cultural and traditional differences may have a substantial impact on marriage and the associated lifestyle changes that could influence body weight (38). Third, some level of bias is inevitable with selfreporting. Fourth, although adjustments were made for various covariates in the models, other confounding factors such as mental and physical health comorbidities may also have a significant impact on weight changes and the risk of being overweight/obese $(39,40)$. Fifth, the long intervals between surveys may not have been adequate to reflect short-term weight changes caused by major life events such as a spouse's death or divorce. Finally, it is not clear whether marital status changes multiple times (e.g., marrieddivorced-remarried) during the period of follow-up, as our study only captured the first and the last time point of the study duration for the individuals.

Despite the increasing evidence of a positive association between marriage and weight gain, the exact mechanism linking overweight and obesity to marriage remains fully understood. Numerous multi-dimensional factors, such as race, age, sex, sociodemographic confounders, socioeconomic status, cultural and religious beliefs, geographical location, and environment, need to be further investigated for their interactions and effects on body weight. Mechanisms through which marital status may influence BMI to include energy intake and expenditure and metabolic changes (20). We speculate that endorphins may also play a role in weight control by exercise among unmarried individuals (22). In contrast, married individuals are extremely unlikely to experience a rise in endorphins due to a lack of exercise, which is an indirect cause of weight gain.

In conclusion, our study has provided evidence that marriage contributed to an increased risk of overweight and obesity among Chinese men and women. Therefore, weight management programs, including nutrition counseling and a physical activity plan, should be specifically targeted at married and divorced/widowed individuals.

\section{Acknowledgments}

This research uses data from the China Health and Nutrition Survey (CHNS). We thank the National Institute of Nutrition and Food Safety (China Center for Disease Control and Prevention), Carolina Population Center (the University of North Carolina at Chapel Hill), and the US National Institutes of Health (Fogarty International Center, and R01-HD30880, DK056350 and R01-HD38700) for their financial support for the collection and analysis of CHNS data from 1989 to 2006 . We also thank the ChinaJapan Friendship Hospital and the Chinese Ministry of Health for their support for the CHNS 2009 and later surveys.

Funding: LZ was supported by the National Natural Science Foundation of China (grant number: 8191101420) and Outstanding Young Scholars Supporting Grant (Grant number: 3111500001); Xi'an Jiaotong University Basic Research and Profession Grant (Grant number: xtr022019003) and Xi'an Jiaotong University Young Talent Support Program (Grant number: YX6J004).

\section{Footnote}

Reporting Checklist: The authors have completed the STROBE reporting checklist. Available at http://dx.doi. org/10.21037/atm-20-4550

Data Sharing Statement: Available at http://dx.doi. org/10.21037/atm-20-4550

Peer Review File: Available at http://dx.doi.org/10.21037/ atm-20-4550

Conflicts of Interest: All authors have completed the ICMJE uniform disclosure form (available at http://dx.doi. org/10.21037/atm-20-4550). The authors have no conflicts of interest to declare.

Ethical Statement: The authors are accountable for all 
aspects of the work in ensuring that questions related to the accuracy or integrity of any part of the work are appropriately investigated and resolved. The study was conducted in accordance with the Declaration of Helsinki (as revised in 2013). The survey protocols, instruments, and the process for obtaining informed consent were approved by the Institutional Review Committees of the University of North Carolina at Chapel Hill, NC, USA, and the China National Institute of Nutrition and Food Safety at the Chinese Center for Disease Control and Prevention, Beijing, China. All participants provided written informed consent prior to the surveys.

Open Access Statement: This is an Open Access article distributed in accordance with the Creative Commons Attribution-NonCommercial-NoDerivs 4.0 International License (CC BY-NC-ND 4.0), which permits the noncommercial replication and distribution of the article with the strict proviso that no changes or edits are made and the original work is properly cited (including links to both the formal publication through the relevant DOI and the license). See: https://creativecommons.org/licenses/by-nc-nd/4.0/.

\section{References}

1. Lundborg P, Nystedt P, Lindgren B. Getting ready for the marriage market? The association between divorce risks and investments in attractive body mass among married Europeans. J Biosoc Sci 2007;39:531-44.

2. Syrda J. The impact of marriage and parenthood on male body mass index: Static and dynamic effects. Soc Sci Med 2017;186:148-55.

3. The NS, Gordon-Larsen P. Entry into romantic partnership is associated with obesity. Obesity 2009;17:1441-7.

4. $\mathrm{Ng} M$, Fleming T, Robinson M, et al. Global, regional, and national prevalence of overweight and obesity in children and adults during 1980-2013: a systematic analysis for the Global Burden of Disease Study 2013. Lancet 2014;384:766-81.

5. Finucane MM, Stevens GA, Cowan MJ, et al. National, regional, and global trends in body-mass index since 1980: systematic analysis of health examination surveys and epidemiological studies with 960 country-years and 9.1 million participants. Lancet (London, England) 2011;377:557-67.

6. Wormser D, Kaptoge S, Di Angelantonio E, et al. Separate and combined associations of body-mass index and abdominal adiposity with cardiovascular disease: collaborative analysis of 58 prospective studies. Lancet 2011;377:1085-95.

7. Zhang L, Shang X, Sreedharan S, et al. Predicting the Development of Type 2 Diabetes in a Large Australian Cohort Using Machine-Learning Techniques: Longitudinal Survey Study. JMIR Med Inform 2020;8:e16850.

8. Liu X, Zhang D, Liu Y, et al. A J-shaped relation of $\mathrm{BMI}$ and stroke: Systematic review and dose-response meta-analysis of 4.43 million participants. Nutr Metab Cardiovasc Dis 2018;28:1092-9.

9. Lakkis JI, Weir MR. Obesity and Kidney Disease. Prog Cardiovasc Dis 2018;61:157-67.

10. Jiang $L$, Tian W, Wang $Y$, et al. Body mass index and susceptibility to knee osteoarthritis: A systematic review and meta-analysis. Joint Bone Spine 2012;79:291-7.

11. Lauby-Secretan B, Scoccianti C, Loomis D, et al. Body Fatness and Cancer--Viewpoint of the IARC Working Group. N Engl J Med 2016;375:794-8.

12. Shang $X$, Peng $W, W u J$, et al. Leading determinants for multimorbidity in middle-aged Australian men and women: A nine-year follow-up cohort study. Prev Med 2020;141:106260.

13. Shang X, Peng W, Hill E, et al. Incidence, Progression, and Patterns of Multimorbidity in Community-Dwelling Middle-Aged Men and Women. Front Public Health 2020;8:404.

14. Shang X, Hodge AM, Peng W, et al. Are Leading Risk Factors for Cancer and Mental Disorders Multimorbidity Shared by These Two Individual Conditions in Community-Dwelling Middle-Aged Adults? Cancers (Basel) 2020;12:1700.

15. Sobal J, Rauschenbach B, Frongillo EA. Marital status changes and body weight changes: a US longitudinal analysis. Soc Sci Med 2003;56:1543-55.

16. Sobal J, Hanson KL, Frongillo EA. Gender, ethnicity, marital status, and body weight in the United States. Obesity (Silver Spring) 2009;17:2223-31.

17. Klos LA, Sobal J. Marital status and body weight, weight perception, and weight management among U.S. adults. Eat Behav 2013;14:500-7.

18. Tzotzas T, Vlahavas G, Papadopoulou SK, et al. Marital status and educational level associated to obesity in Greek adults: data from the National Epidemiological Survey. BMC Public Health 2010;10:732.

19. Liao C, Gao W, Cao W, et al. Association of Educational Level and Marital Status With Obesity: A Study of 
Chinese Twins. Twin Res Hum Genet 2018;21:126-35.

20. Janghorbani M, Amini M, Rezvanian H, et al. Association of body mass index and abdominal obesity with marital status in adults. Arch Iran Med 2008;11:274-81.

21. Jeffery RW, Rick AM. Cross-sectional and longitudinal associations between body mass index and marriage-related factors. Obes Res 2002;10:809-15.

22. Singh DK, Tuli L. Obesity and its mechanisms--who to blame after marriage? Med Hypotheses 2010;75:472-3.

23. Taheri S, Lin L, Austin D, et al. Short sleep duration is associated with reduced leptin, elevated ghrelin, and increased body mass index. PLoS Med 2004;1:e62.

24. Averett SL, Sikora A, Argys LM. For better or worse: relationship status and body mass index. Econ Hum Biol 2008;6:330-49.

25. Chen Y, Peng Q, Yang Y, et al. The prevalence and increasing trends of overweight, general obesity, and abdominal obesity among Chinese adults: a repeated crosssectional study. BMC Public Health 2019;19:1293.

26. Ministry of Civil Affairs of China. Statistical bulletin on the development of civil affairs. 2019. Available online: http://www.mca.gov.cn/article/sj/tjgb/? Accessed 25st Dec, 2019.

27. Raymo JM, Park H, Xie Y, et al. Marriage and Family in East Asia: Continuity and Change. Annu Rev Sociol 2015;41:471-92.

28. Hetherington EM, Stanley-Hagan M. The adjustment of children with divorced parents: a risk and resiliency perspective. J Child Psychol Psychiatry 1999;40:129-40.

29. Umberson D, Liu H, Powers D. Marital status, marital transitions, and body weight. J Health Soc Behav 2009;50:327-43.

30. Xu H. Developmental Idealism, Body Weight and Shape,

Cite this article as: Liu J, Garstka MA, Chai Z, Chen Y, Lipkova V, Cooper ME, Mokoena KK, Wang Y, Zhang L. Marriage contributes to higher obesity risk in China: findings from the China Health and Nutrition Survey. Ann Transl Med 2021;9(7):564. doi: 10.21037/atm-20-4550 and Marriage Entry in Transitional China. Chin J Sociol 2016;2:235-58.

31. National Buearu of Statistis of China. The Statistical Yearbook of China. 2019. Available online: http://www. stats.gov.cn/tjsj/ndsj/. Accessed 21st Dec, 2019.

32. Zhou BF; Cooperative Meta-Analysis Group of the Working Group on Obesity in China. Predictive values of body mass index and waist circumference for risk factors of certain related diseases in Chinese adults--study on optimal cut-off points of body mass index and waist circumference in Chinese adults. Biomed Environ Sci 2002;15:83-96.

33. Lu J, Bi Y, Ning G. Curbing the obesity epidemic in China. Lancet Diabetes Endocrinol 2016;4:470-1.

34. Seidell JC, Halberstadt J. The global burden of obesity and the challenges of prevention. Ann Nutr Metab 2015;66 Suppl 2:7-12.

35. Kiecolt-Glaser JK, Newton TL. Marriage and health: his and hers. Psychol Bull 2001;127:472-503.

36. Wilson SE. Marriage, gender and obesity in later life. Econ Hum Biol 2012;10:431-53.

37. Teachman J. Body Weight, Marital Status, and Changes in Marital Status. J Fam Issues 2016;37:74-96.

38. Gubhaju L, Banks E, Macniven R, et al. Factors relating to participation in follow-up to the 45 and up study in Aboriginal and non-Aboriginal individuals. BMC Med Res Methodol 2016;16:53.

39. Moazzami K, Lima BB, Sullivan S, Shah A, Bremner JD, Vaccarino V. Independent and joint association of obesity and metabolic syndrome with depression and inflammation. Health Psychol 2019;38:586-95.

40. Gove WR, Hughes M, Style CB. Does marriage have positive effects on the psychological well-being of the individual? J Health Soc Behav 1983;24:122-31. 
Table S1 Distribution of cohort participants by starting and ending year of the survey

\begin{tabular}{|c|c|c|c|c|c|}
\hline \multirow[t]{2}{*}{ Starting } & \multicolumn{4}{|c|}{ Ending } & \multirow[t]{2}{*}{ Total } \\
\hline & 2006 & 2009 & 2011 & 2015 & \\
\hline 2004 & 862 & 699 & 1864 & 1881 & 5306 \\
\hline 2006 & 0 & 242 & 590 & 578 & 1410 \\
\hline 2009 & 0 & 0 & 642 & 666 & 1308 \\
\hline 2011 & 0 & 0 & 0 & 1622 & 1622 \\
\hline Total & 862 & 941 & 3096 & 4747 & 9646 \\
\hline
\end{tabular}

Table S2 Prevalence (\%, 95\% CI) of overweight and obesity (BMI $\geq 24.0)$ by marital status and other demographic characteristics among participants of CHNS in a pooled dataset of the five consecutive longitudinal surveys $(\mathrm{N}=36,310)$

\begin{tabular}{|c|c|c|c|}
\hline Characteristics & Never-married $(n=1729)$ & Married $(n=32014)$ & Divorced/Widowed $(n=2567)$ \\
\hline \multicolumn{4}{|l|}{ Sex } \\
\hline Men & $28.0(25.3-30.7)$ & $45.3(44.5-46.0)$ & $37.9(34.6-41.1)$ \\
\hline Women & $13.8(11.2-16.4)$ & $42.5(41.7-43.3)$ & $42.2(39.8-44.5)$ \\
\hline$P$ value & $<0.0001$ & $<0.0001$ & 0.0377 \\
\hline \multicolumn{4}{|l|}{ Age groups } \\
\hline $18-29$ & 19.8(17.6-21.9) & $27.3(25.0-29.5)$ & $24.0(9.36-45.1)$ \\
\hline $30-39$ & $30.4(24.3-36.4)$ & $36.6(35.4-37.9)$ & $27.7(20.7-34.8)$ \\
\hline $40-49$ & 28.7(19.6-37.9) & $46.2(45.2-47.3)$ & $42.9(37.1-48.7)$ \\
\hline $50-59$ & 23.2(13.2-33.2) & $47.8(46.8-48.9)$ & $47.6(43.3-51.9)$ \\
\hline $60-69$ & $37.0(23.0-50.9)$ & $47.2(45.9-48.5)$ & $41.8(38.1-45.5)$ \\
\hline $70-79$ & $23.5(6.8-49.9)$ & $43.1(41.0-45.2)$ & $41.3(37.5-45.0)$ \\
\hline$\geq 80$ & $66.6(13.3-1.00)$ & $30.8(25.9-35.8)$ & $28.7(22.9-34.5)$ \\
\hline$P$ value/ $P$ trend & $<0.0001 /<0.0001$ & $<0.0001 /<0.0001$ & $<0.0001 /<0.0001$ \\
\hline \multicolumn{4}{|l|}{ Residence } \\
\hline Urban & $27.6(24.6-30.6)$ & $49.9(49.0-50.7)$ & $48.2(45.6-50.9)$ \\
\hline Rural & $17.0(14.5-19.5)$ & $38.8(38.1-39.6)$ & $32.2(29.6-34.9)$ \\
\hline$P$ value & $<0.0001$ & $<0.0001$ & $<0.0001$ \\
\hline \multicolumn{4}{|l|}{ Education } \\
\hline Primary school and below & 18.6(13.6-23.5) & $41.2(40.3-42.1)$ & $37.4(34.9-39.9)$ \\
\hline Middle/high school & $22.4(19.8-24.9)$ & $45.2(44.5-46.0)$ & $45.6(42.4-48.8)$ \\
\hline University/higher & $24.1(20.2-28.0)$ & $46.0(44.3-47.7)$ & $42.9(35.4-50.5)$ \\
\hline$P$ value/ $P$ trend & $0.2470 / 0.2470$ & $<0.0001 /<0.0001$ & $0.0003 / 0.0003$ \\
\hline \multicolumn{4}{|l|}{ Employment status } \\
\hline Unemployed & $21.9(16.0-27.9)$ & $50.0(49.0-50.9)$ & $44.8(42.3-47.3)$ \\
\hline Employed & $22.4(20.3-24.5)$ & $41.2(40.6-41.9)$ & $35.3(32.5-38.2)$ \\
\hline$P$ value & 0.8894 & $<0.0001$ & $<0.0001$ \\
\hline \multicolumn{4}{|l|}{ Income levels (yuan) ${ }^{a}$} \\
\hline Low income & 17.7(13.8-21.6) & $40.7(39.4-41.9)$ & $34.0(30.4-37.6)$ \\
\hline Middle income & 23.4(20.8-26.0) & $44.2(43.5-44.9)$ & $42.5(40.1-44.9)$ \\
\hline High income & $24.1(19.4-28.7)$ & $46.4(45.1-47.7)$ & $45.9(40.2-51.6)$ \\
\hline$P$ value/ $P$ trend & $0.0561 / 0.0561$ & $<0.0001 /<0.0001$ & $0.0002 /<0.0001$ \\
\hline \multicolumn{4}{|l|}{ Sleep time(hours) } \\
\hline$\leq 5$ hours & $20.0(4.3-48.1)$ & $44.7(40.8-48.6)$ & $39.7(31.0-48.4)$ \\
\hline $6-8$ hours & $23.1(20.8-25.5)$ & $44.9(44.3-45.6)$ & $41.8(39.5-44.1)$ \\
\hline$\geq 9$ hours & $20.0(16.2-23.8)$ & $40.0(38.8-41.2)$ & $38.1(34.4-41.8)$ \\
\hline$P$ value/ $P$ trend & $0.3877 / 0.3877$ & $<0.0001 /<0.0001$ & $0.2529 / 0.2529$ \\
\hline \multicolumn{4}{|l|}{ Smoking } \\
\hline No & 20.5(18.3-22.8) & $44.8(44.1-45.5)$ & $42.3(40.1-44.5)$ \\
\hline Yes & $26.4(22.7-30.2)$ & $42.1(41.2-43.0)$ & $36.1(32.4-39.8)$ \\
\hline$P$ value & 0.0068 & $<0.0001$ & 0.0057 \\
\hline \multicolumn{4}{|l|}{ Alcohol consumption } \\
\hline No & $19.5(17.2-21.8)$ & $43.2(42.5-43.8)$ & $41.1(39.0-43.3)$ \\
\hline Yes & $27.7(24.1-31.3)$ & 45.3(44.4-46.2) & $39.5(35.7-43.4)$ \\
\hline$P$ value & 0.0001 & 0.0002 & 0.4746 \\
\hline
\end{tabular}

CHNS: China Health and Nutrition Surveys. 
Table S3 Risk of underweight, overweight and obesity in participants who remained married compared with participants who became married, in a pooled cohort of CNHS participants across five consecutive longitudinal surveys $(\mathrm{n}=8,580)$ Data are risk ratio (RR) and $95 \%$ CIs (versus normal weight)

\begin{tabular}{|c|c|c|c|}
\hline Total( Marital status change) & Model 1 & Model 2 & Model 3 \\
\hline \multicolumn{4}{|c|}{ Underweight (ref: Normal weight) } \\
\hline Become married & 1.00 & 1.00 & 1.00 \\
\hline Remain married & $0.57(0.35-0.94)$ & $0.56(0.34-0.94)$ & $0.56(0.34-0.93)$ \\
\hline \multicolumn{4}{|l|}{ Overweight(ref: Normal weight) } \\
\hline Become married & 1.00 & 1.00 & 1.00 \\
\hline Remain married & $1.10(0.85-1.42)$ & $1.14(0.88-1.47)$ & $1.12(0.87-1.45)$ \\
\hline \multicolumn{4}{|l|}{ Obesity (ref: Normal weight) } \\
\hline Become married & 1.00 & 1.00 & 1.00 \\
\hline Remain married & $1.15(0.79-1.67)$ & $1.21(0.83-1.76)$ & $1.17(0.81-1.70)$ \\
\hline
\end{tabular}

Model 1 adjusted for variables in model 1 as well as gender and age, the duration in the cohort at baseline;Model 2 adjusted for variables in model 2 as well as education level, income level, residence, employment status at baseline;Model 3 adjusted for variables in model 3 as well as sleep time, smoking, alcohol consumption at baseline.Variables assignment: gender: male=1, female=2; age: a continuous variable; the duration in the cohort: a continuous variable; education: primary school and below=1, middle/high school=2, university/higher=3 income levels: low income $=1$, middle income $=2$, high income $=3$; residence: urban=1,rural=2; employment status: unemployed=0, employed=1; sleep time: a continuous variable; smoking: $n o=0$, yes $=1$; alcohol consumption: $n o=0$, yes $=1$. CHNS: China Health and Nutrition Survey; Cl: confidence interval. 